\title{
Monitoring the noise level around the Jiu Valley mines using Bruel\&Kjaer noise dose meter type 4448
}

\author{
Alexandra Stanimirescu Soica ${ }^{1 *}$, Florin Flavius Soica $^{2}$, Angela Egri $^{3}$, and Mirela Ancuta \\ Radu $^{4}$ \\ 1 University of Petrosani, Department of Mechanical, Industrial and Transport Engineering, \\ University Street 20, Petrosani, Romania \\ ${ }^{2}$ S CEH SA, Lunca Street 60, Petrosani, Romania \\ 3 University of Petrosani, Department of Mechanical, Industrial and Transport Engineering, \\ University Street 20, Petrosani, Romania \\ ${ }^{4}$ INCD INSEMEX, General Vasile Milea Street 32-34, Petrosani, Romania
}

\begin{abstract}
This paper studies the noise level near the mines in the Jiu Valley using the Bruel \& Kjaer Noise Dose Meter Type 4448. The purpose of the paper is to determine the noise level and how it can be reduced so that it falls within the limits imposed by law. The monitoring was done for a period of three months, during which we analyzed and compared the data with the values established by law. The results of our monitoring showed that the noise due to mining activities has a rather influential aspect in terms of occupational safety and security and does not directly affect daily life.
\end{abstract}

\section{Introduction}

The Jiu Valley is a region in southwestern Transylvania, Romania, in Hunedoara county, situated in a valley of the Jiu River between the Retezat Mountains and the Parâng Mountains. The region was heavily industrialised and the main activity was coal mining, but due to low efficiency, most of the mines were closed down. The region was populated since ancient times, being part of Dacia. During the Middle Ages, the inhabitants of the Jiu Valley lived in huts spread along the mountains, and often near the river, and the main activity was shepherding. The development of coal mining started in the Jiu Valley about 160 years ago, around the middle of the 19th century, when Hungarian, German, Czech and Polish workers were brought from all parts of the Habsburg Empire to work in the coal mines [1].

In physics, sound is a vibration that propagates as an acoustic wave, through a transmission medium such as a gas, liquid or solid. Sound represents the oscillation, voltage, displacement and speed of particles in an environment with different forces. It can move in the form of longitudinal or transverse waves.

\footnotetext{
*Corresponding author: alexandra_valynikalay@yahoo.com
} 
Noise pollution is the spread of noise on the environment and its effects on the human and animal body. Worldwide, the source of external noise is mainly determined by transport and industrial equipment, but also by poor urban planning. The World Health Union has set the value of the noise level in residential areas to be $50 \mathrm{~dB}$, and according to some studies this value is exceeded in most of the world. Research suggests noise pollution is much higher in low-income neighbourhoods and racial minorities. High noise levels can contribute to the development of cardiovascular and coronary heart disease in humans, and in animals noise can increase the risk of death by altering the detection and avoidance of predators or prey.

At the national level, in cities with more than 250,000 inhabitants we find people exposed to noise above the limit provided by environmental standards, which means that for more than $60 \%$ of the population the quality of life is significantly affected by noise pollution [2-7].

\section{Materials and methods}

A wide range of measuring equipment is available, covering the various needs of noise evaluation process. For the measurements we chose Personal Noise Dose Meter Type 4448. This helps to measure and collect data to evaluate noise exposure.

Type 4448 measures all parameters required by the ISO, ANSI and OSHA standard. The parameters are recorded at one minute intervals providing an overview of the noise history. When the noise level is deposited, the device is programmed to emit and transmit alarm signals. The alarm levels will depend on the selected display mode, namely the selection of ISO or OSHA standards. For ISO mode, alarm levels are based on EU Directive 2003/10 / EC, and OSHA levels are based on the US Occupational Health and Safety Administration (OSHA). Measurements to determine the level of noise pollution were carried out in accordance with STAS 10009 - 88 - "URBAN ACOUSTICS Permissible noise level limits", using the calibrated Personal Noise Dose Meter Type 4448 and the QC 20 IEC 942: 1988 Class 1 acoustic calibrator. accuracy and which meets the requirements of IEC 60651 , respectively with the measuring range $30-130 \mathrm{~dB}$ and the measurement error of $+/-0.1 \mathrm{~dB}[8]$.

Taking into account the provisions of STAS 10009/88 - Urban acoustics - Maximum allowed limits of the noise level, allowed in the industrial premises is between 80 and 100 $\mathrm{dB}$.

According to Law no. 121/2019 on noise assessment and management, the noise level in quiet environments, such as residential areas, hospitals, low-traffic streets, the noise level is between 40 and 50 decibels. In noisy areas, such as supermarkets or some work areas, the noise level is between 65 and 80 decibels, and in very noisy environments, such as industrial areas or airports, the permitted noise levels are between 80 and 100 decibels. Regular exceedances of these values affect human health. According to article no. 3 of the Ministerial Order no. 536/1997, the noise level is measured from a distance of 3 meters from the source, and during the night the allowed limit values for the noise level are reduced by 10 decibels.

This paper analyzes the noise level in the mining area of the Jiu Valley. Like any urban environment, the Jiu Valley has several noise sources, namely:

- noise resulting from transport - road, air or rail transport.

- industrial noise - coal extraction and preparation, ventilation stations, unloading points for coal wagons, crushing installations, etc.

- other sources of noise emissions - related to recreational or household activities 
We conducted a study of the noise level in three key points in the Jiu Valley, namely the perimeter of the Livezeni mine, the perimeter of the Lupeni mine and the perimeter of the Vulcan mine.

In terms of noise and vibration, it must be taken into account that the mining units are located in the perimeter of the localities, near the residential neighborhoods and for this reason they can become the main factor responsible for noise pollution.

Although the equipment is generally equipped with noise-reducing means, the measurements carried out have shown that there are frequent exceedances of the maximum permissible value of $90 \mathrm{~dB}$ (limit allowed in workplaces within mining units).

\section{Results}

The measurements were performed over a period of three months, namely December 2020, January 2021 and February 2021 at different times of the day. The three months were divided into periods of ten days, at the end of which the average presented in the graphs below was made.

The graph below represented by Figure 1 shows the values of the noise level in the perimeter of the Livezeni mine during three months. December 2020 shows the highest values of decibels recorded by us, namely about 79 decibels, 99 decibels and 88 decibels.

We can say about it that the registered values exceed the values established by law. January 2021 has values of decibels approximately equal to those of December 2020, namely approximately 63 decibels, 99 decibels and 88 decibels. We can also say about this that the registered values exceed the values established by law. February 2021 has the lowest decibel values compared to previous months, namely about 65 decibels, 50 decibels and 20 decibels. We can say about this month that it falls within the values established by law.

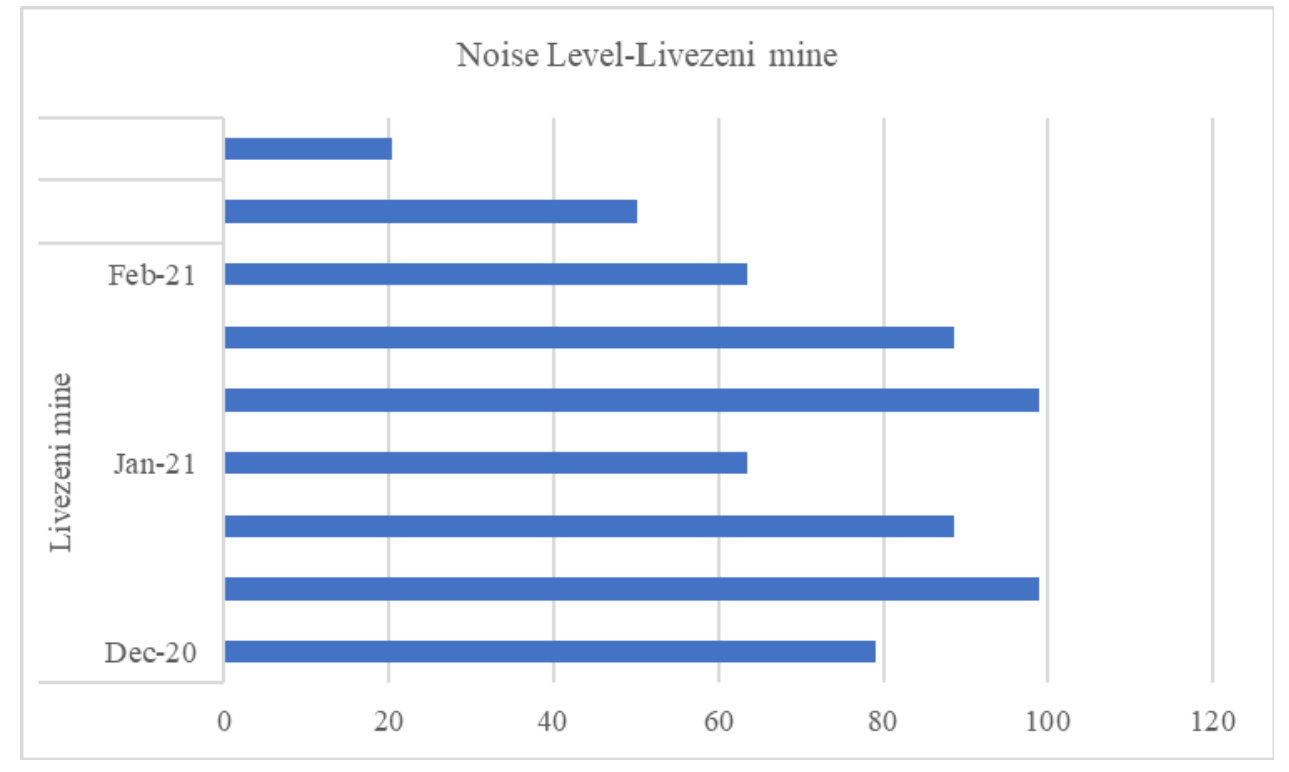

Fig. 1. Noise level in the perimeter of Livezeni Mine.

The graph belowe represented by Figure 2 shows the values of the noise level in the perimeter of the Lupeni mine during three months. As at the Livezeni mine and the Lupeni mine, it register the highest values in December 2020, namely about 99 decibels, 58 
decibels and 90 decibels. We can say about it that the registered values exceed the values established by law. January 2021 has approximate decibel values of 65 decibels, 79 decibels and 90 decibels. We can also say about this that the registered values exceed the values established by law. February 2021 has the lowest decibel values compared to previous months, namely about 63 decibels, 50 decibels and 48 decibels. We can say about this month that it falls within the values established by law.

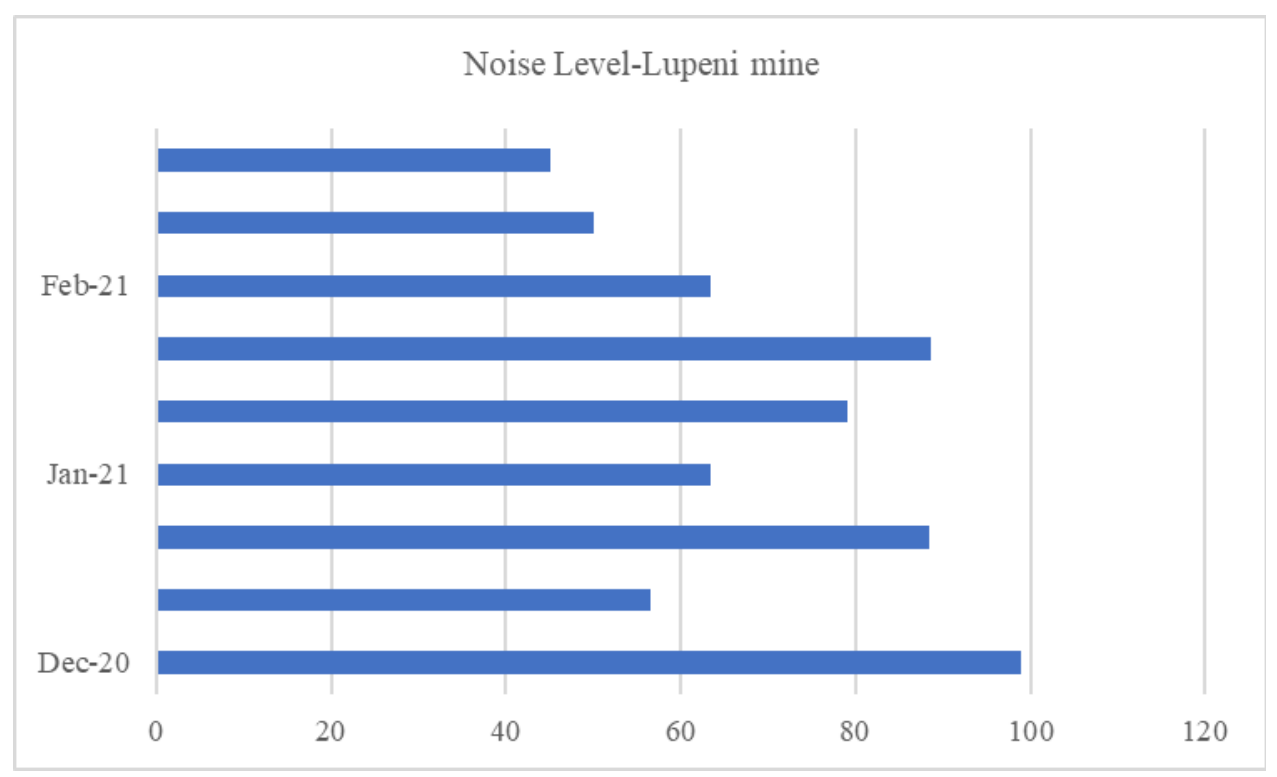

Fig. 2. Noise level in the perimeter of Lupeni Mine.

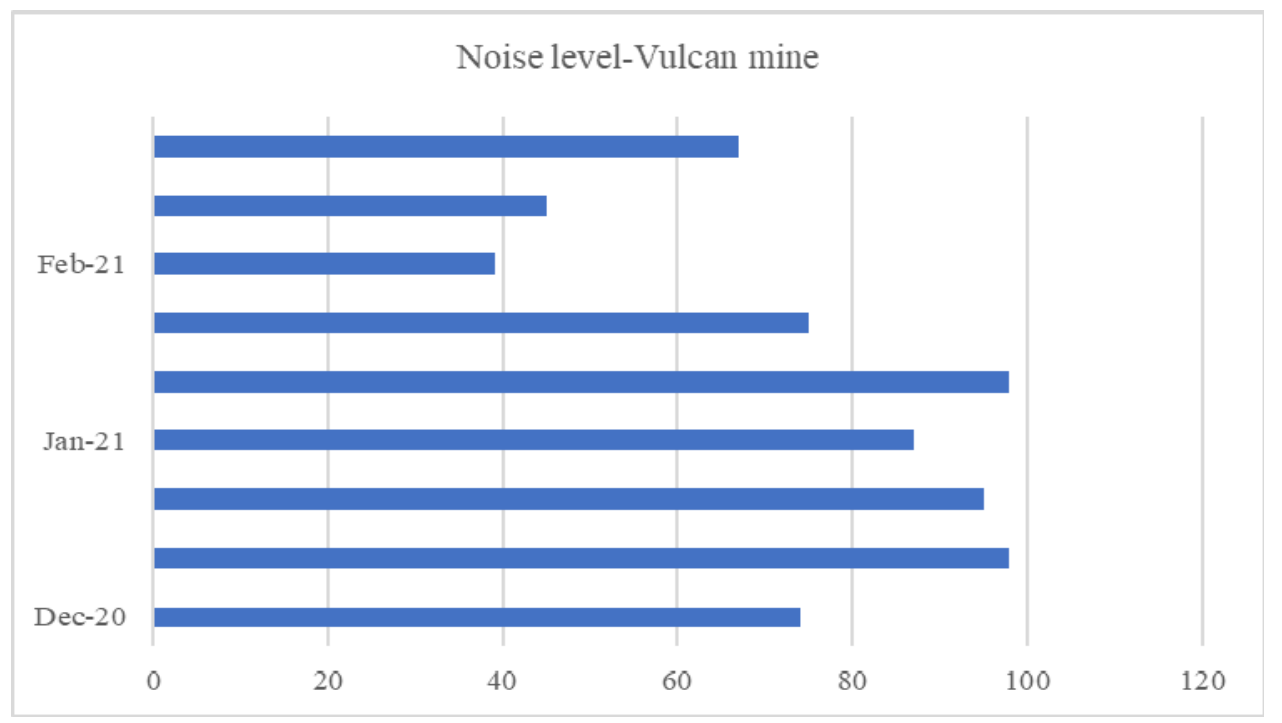

Fig. 3. Noise level in the perimeter of Vulcan Mine.

The graph above represented by Figure 3 shows the values of the noise level in the perimeter of the Vulcan mine during three months. As well as the other mining units presented above, it also has the highest values in December 2020, namely about 74 
decibels, 98 decibels and 87 decibels. We can say about it that the registered values exceed the values established by law. January 2021 has approximate decibel values of 86 decibels, 98 decibels and 75 decibels. We can also say about this that the registered values exceed the values established by law. February 2021 has the lowest decibel values compared to previous months, namely about 39 decibels, 53 decibels and 67decibels. We can say about this month that it falls within the values established by law.

\section{Discussions and conclusions}

Environmental pollution has become one of the most important human problems. Man and the environment are inseparable structures, they are permanently dependent on each other, and the components of the environment (water, air, soil) can change, following their use by humans. Thus, pollution appears, an implicit aspect of life, in the development of which some products become residues that affect the well-being of humans and animals depending on their nature and quantity.

Mining activity, regardless of how it is carried out, always produces long-term negative effects on the environment, and one of the areas in Romania where the environment has suffered from anthropogenic activities is that of Jiu Valley (Petroșani Depression), the area where the main activity mining has been and continues to be mining.

In terms of noise and vibration, it must be taken into account that the mining units are located in the perimeter of the localities, near the residential neighborhoods and for this reason they can become the main factor responsible for noise pollution.

The measurements made over a period of 3 months showed us that the values measured near the Lupeni, Vulcan and Livezeni mines quite often exceed the values imposed by the Romanian legislature.

The measurements carried out at a distance from the above-mentioned premises do not indicate exceedances of the rules in force. It can be concluded that the noise due to mining activities has a rather influential aspect in terms of occupational safety and security.

One way to reduce noise and vibration around mines would be to replace equipment with newer and more efficient ones and create natural barriers around mines.

\section{References}

1. S.I. Irimie, S.M. Radu, D.C. Petrilean, A. Andras, Reducing the environmental impact of a gas operated cogeneration installation (Matec Web of Conferences, 2017)

2. F.F. Şoica, A. Egri, A. Stanimirescu, Analysis of quality indicators from slurry decanters (Annals of the University of Petrosani Mechanical Engineering, 2018)

3. A. Stanimirescu, A. Egri, F.F. Soica, S.M. Radu, Measuring the change of air temperature with 8 LM75A sensors in mining area (MATEC Web of Conferences, 2020)

4. A. Stanimirescu, A. Egri , The quality of the environment in the city of petrosani in the opinion of citizens'(Annals of the University of Petrosani Mechanical Engineering, 2019)

5. E.C Dunca; I.D. Ciolea, Risk assessment pollution and ecotoxicological effects in sites abandoned mining industry in Romania (Annals of the University of Petrosani Mining Engineering, 2014)

6. A Stanimirescu, A Egri, F.F. Șoica, the effects of the mining industry on the jiu river in the opinion of the citizens. Case study (Annals of the University of Petroşani, Mechanical Engineering,2020)

7. Jiu Valley on https://www.wikipedia.ro/

8. Personal Noise Dose Meter Type 4448 User Guide. Available on https://www.bksv.com 